\title{
Implementation and Comparison of Different Transform Techniques using Kekre's Wavelet Transform for Image Fusion
}

\author{
H.B. Kekre \\ MPSTME, SVKM' \\ NMIMS university
}

\author{
Tanuja Sarode \\ Computer engineering dept., \\ Thadomal Shahani Engineering college
}

\author{
Rachana Dhannawat \\ Computer Sci. \& Technology dept. \\ S.N.D.T. University, Mumbai
}

\begin{abstract}
Image fusion combines several images of same object or scene so that the final output image contains more information. In this paper many advanced pixel level fusion techniques like Kekre's wavelet transform, DCT Kekre's wavelet transform, Hadamard Kekre's wavelet transform, Walsh Kekre's wavelet transform techniques for image fusion are proposed and compared. These methods have main advantage that they can be used for images whose sizes are not necessarily integer power of 2 .
\end{abstract}

\section{General Terms}

Image Fusion, algorithm

\section{Keywords}

DCT Kekre's wavelet, Hadamard Kekre's wavelet, Walsh Kekre's wavelet, image fusion.

\section{INTRODUCTION}

Image fusion is the technology that combines several images of the same area or the same object under different imaging conditions. In other words, it is used to generate a result which describes the scene "better" than any single image with respect to relevant properties; it means the acquisition of perceptually important information. The main requirement of the fusion process is to identify the most significant features in the input images and to transfer them without loss of detail into the fused image. The final output image can provide more information than any of the single images as well as reducing the signal-to-noise ratio.

The objective of image fusion is to obtain a better visual understanding of certain phenomena, and to enhance intelligence and system control functions. The data gathered from multiple sources of acquisition are delivered to preprocessing such as denoising and image registration. This step is used to associate the corresponding pixels to the same physical points on the object. In this method, the input images can be compared pixel by pixel. The post-processing is applied to the fused image. Post-processing includes classification, segmentation, and image enhancement.

Many image fusion techniques pixel level, feature level and decision level are developed. Examples are like Averaging technique [4] [7], PCA [7], [8], [11] pyramid transform, wavelet transform, neural network, K-means clustering, etc. Several situations in image processing require high spatial and high spectral resolution in a single image. For example, the traffic monitoring system, satellite image system, and long range sensor fusion system, land surveying and mapping, geologic surveying, agriculture evaluation, medical and weather forecasting all use image fusion.

Like these, applications motivating the image fusion are: Image Classification, Aerial and Satellite imaging, Medical imaging, Robot vision, Concealed weapon detection, Multi- focus image fusion, Digital camera application, Battle field monitoring, etc [10].

\section{PIXEL LEVEL FUSION TECHNIQUES:}

\subsection{Averaging Technique [4] [7]:}

This technique is a basic and straight forward technique and fusion could be achieved by simple averaging corresponding pixels in each input image as

$\mathrm{F}(\mathrm{m}, \mathrm{n})=(\mathrm{A}(\mathrm{m}, \mathrm{n})+\mathrm{B}(\mathrm{m}, \mathrm{n})) / 2$

\subsection{Principal Components Analysis [8] [11]:}

In this method the eigenvector and eigen values of input image vector are Computed and the eigenvectors corresponding to the larger eigen value obtained, and

The fused image is:

$$
I_{f}(x, y)=P_{1} I_{1}(x, y)+P_{2} I_{2}(x, y)
$$

where $\mathrm{P}_{1}$ and $\mathrm{P} 2$ are the normalized components and its equal to $\mathrm{P}_{1}=\mathrm{V}(1) / \sum \mathrm{V}$ and $\mathrm{P}_{2}=\mathrm{V}(2) / \sum \mathrm{V}$ where $\mathrm{V}$ is eigen vector and $\mathrm{P}_{1}+\mathrm{P}_{2}=1$.

\subsection{Discrete Cosine Transform Technique:}

In this technique images are divided into blocks then we calculate the DCT representations and take their average for corresponding blocks. Finally taken the inverse discrete cosine transform to reconstruct the fused image. Actually, this image fusion technique is called the DCT + average; modified or "improved" DCT technique [5][11].

\subsection{Discrete Wavelet Transform Technique with Haar [1] based fusion:}

It uses fast Mallet's transform [1], the algorithm first decomposes both input imagess to get an approximate image and a detail image. Images are fused using the fusion rules. The resulting fused transform is reconstructed to fused image by inverse wavelet transformation

The Haar wavelet is the first known wavelet. The $2 \times 2$ Haar matrix that is associated with the Haar wavelet is

$H_{2}=\frac{1}{\sqrt{2}}\left[\begin{array}{cc}1 & 1 \\ 1 & -1\end{array}\right]$

$4 \mathrm{x} 4$ Haar transformation matrix is shown below. 


$$
\mathrm{H}_{4}=\frac{1}{\sqrt{4}}\left[\begin{array}{cccc}
1 & 1 & 1 & 1 \\
1 & 1 & 1 & 1 \\
\sqrt{2} & -\sqrt{2} & 0 & 0 \\
0 & 0 & \sqrt{2} & -\sqrt{2}
\end{array}\right]
$$

\section{KEKRE'S TRANSFORM [6] [9]:}

Kekre's transform matrix can be of any size $\mathrm{NxN}$, which need not to be an integer power of 2. All upper diagonal and diagonal elements of Kekre's transform matrix are 1, while the lower diagonal part except the elements just below diagonal is zero. Generalized NxN Kekre's transform matrix can be given as shown in (5)

$$
\left[\begin{array}{cccccc}
1 & 1 & 1 & \ldots & 1 & 1 \\
-N+1 & 1 & 1 & \ldots & 1 & 1 \\
0 & -\mathrm{N}+2 & 1 & \ldots & 1 & 1 \\
. & . & . & \ldots & . & . \\
. & . & . & \ldots & . & . \\
. & . & . & \ldots & . & . \\
0 & 0 & 0 & \ldots & 1 & 1 \\
0 & 0 & 0 & \ldots & -N+(N-1) & 1
\end{array}\right]
$$

The formula for generating the element Kxy of Kekre's transform matrix

$$
K x y= \begin{cases}1 & : x \leq y \\ -N+(x-1) & : x=y+1 \\ 0 & : x>y+1\end{cases}
$$

\section{Kekre's Wavelet Transform [6] [9]:}

Kekre's Wavelet transform is derived from Kekre's transform. From $\mathrm{NxN}$ Kekre's transform matrix, we can generate Kekre's Wavelet transform matrices of size $(2 \mathrm{~N}) \mathrm{x}(2 \mathrm{~N})$, $(3 \mathrm{~N}) \mathrm{x}(3 \mathrm{~N}), \ldots \ldots,(\mathrm{N} 2) \times(\mathrm{N} 2)$. For example, from $5 \times 5$ Kekre's transform matrix, we can generate Kekre's Wavelet transform matrices of size $10 \times 10,15 \times 15,20 \times 20$ and $25 \times 25$. In general MxM Kekre's Wavelet transform matrix can be generated from NxN Kekre's transform matrix, such that $\mathrm{M}=\mathrm{N} * \mathrm{P}$ where $\mathrm{P}$ is any integer between 2 and $\mathrm{N}$ that is, $2 \leq \mathrm{P} \leq \mathrm{N}$. Consider the Kekre's transform matrix of size NxN shown in Figure 1.
Figure 2 shows MxM Kekre's Wavelet transform matrix generated from $\mathrm{NxN}$ Kekre's transform matrix. First $\mathrm{N}$ numbers of rows of Kekre's Wavelet transform matrix are generated by repeating every column of Kekre's transform matrix $\mathrm{P}$ times. To generate remaining (M-N) rows, extract last ( $\mathrm{P}-1)$ rows and last $\mathrm{P}$ columns from Kekre's transform matrix and store extracted elements in to temporary matrix say $\mathrm{T}$ of size $(\mathrm{P}-1)$ x $\mathrm{P}$. Figure 3 shows extracted elements of Kekre's transform matrix stored in $\mathrm{T}$.

\begin{tabular}{|l|l|l|l|l|l|}
\hline $\mathrm{K}_{11}$ & $\mathrm{~K}_{12}$ & $\mathrm{~K}_{13}$ & $\cdots$ & $\mathrm{K}_{1(\mathrm{~N}-1)}$ & $\mathrm{K}_{1 \mathrm{~N}}$ \\
\hline $\mathrm{K}_{21}$ & $\mathrm{~K}_{22}$ & $\mathrm{~K}_{23}$ & $\cdots$ & $\mathrm{K}_{2(\mathrm{~N}-1)}$ & $\mathrm{K}_{2 \mathrm{~N}}$ \\
\hline $\mathrm{K}_{31}$ & $\mathrm{~K}_{32}$ & $\mathrm{~K}_{33}$ & $\cdots$ & $\mathrm{K}_{3(\mathrm{~N}-1)}$ & $\mathrm{K}_{3 \mathrm{~N}}$ \\
\hline$\cdot$ & $\cdot$ & $\cdot$ & $\cdots$ & $\cdot$ & $\cdot$ \\
$\cdot$ & $\cdot$ & $\cdot$ & & $\cdot$ & $\cdot$ \\
\hline $\mathrm{K}_{\mathrm{N} 1}$ & $\cdot$ & $\cdot$ & & $\cdot$ & $\cdot$ \\
\hline
\end{tabular}

Figure 1 Kekre's Transform (KT) matrix of size $\mathrm{NxN}$

\begin{tabular}{|l|l|l|l|}
\hline $\mathrm{K}_{(\mathrm{N}-\mathrm{P}+2)(\mathrm{N}-\mathrm{P}+1)}$ & $\mathrm{K}_{(\mathrm{N}-\mathrm{P}+2)(\mathrm{N}-\mathrm{P}+2)}$ & $\cdots$ & $\mathrm{K}_{(\mathrm{N}-\mathrm{P}+2) \mathrm{N}}$ \\
\hline $\mathrm{K}_{(\mathrm{N}-\mathrm{P}+3)(\mathrm{N}-\mathrm{P}+1)}$ & $\mathrm{K}_{(\mathrm{N}-\mathrm{P}+3)(\mathrm{N}-\mathrm{P}+2)}$ & $\cdots$ & $\mathrm{K}_{(\mathrm{N}-\mathrm{P}+3) \mathrm{N}}$ \\
\hline$\cdot$ & $\cdot$ & $\cdots$ & $\cdot$ \\
$\cdot$ & $\cdot$ & & $\cdot$ \\
\hline $\mathrm{K}_{\mathrm{N}(\mathrm{N}-\mathrm{P}+1)}$ & $\cdot$ & & $\cdot$ \\
\hline
\end{tabular}

Figure 3 Temporary matrix $T$ of size $(P-1)$ x $P$

In the same way DCT kekre's wavelet Technique, Hadamard kekre's wavelet Technique and Walsh kekre's wavelet Technique are implemented. In these techniques instead of using Kekre's transform matrix as base matrix the respective transform matrices are used as base matrices and then wavelet matrix is generated by the above illustrated technique 
$1^{\text {st }}$ column of kekre's transform repeated $\mathrm{P}$ times $2^{\text {nd }}$ column of kekre's

transform repeated $\mathrm{P}$ times

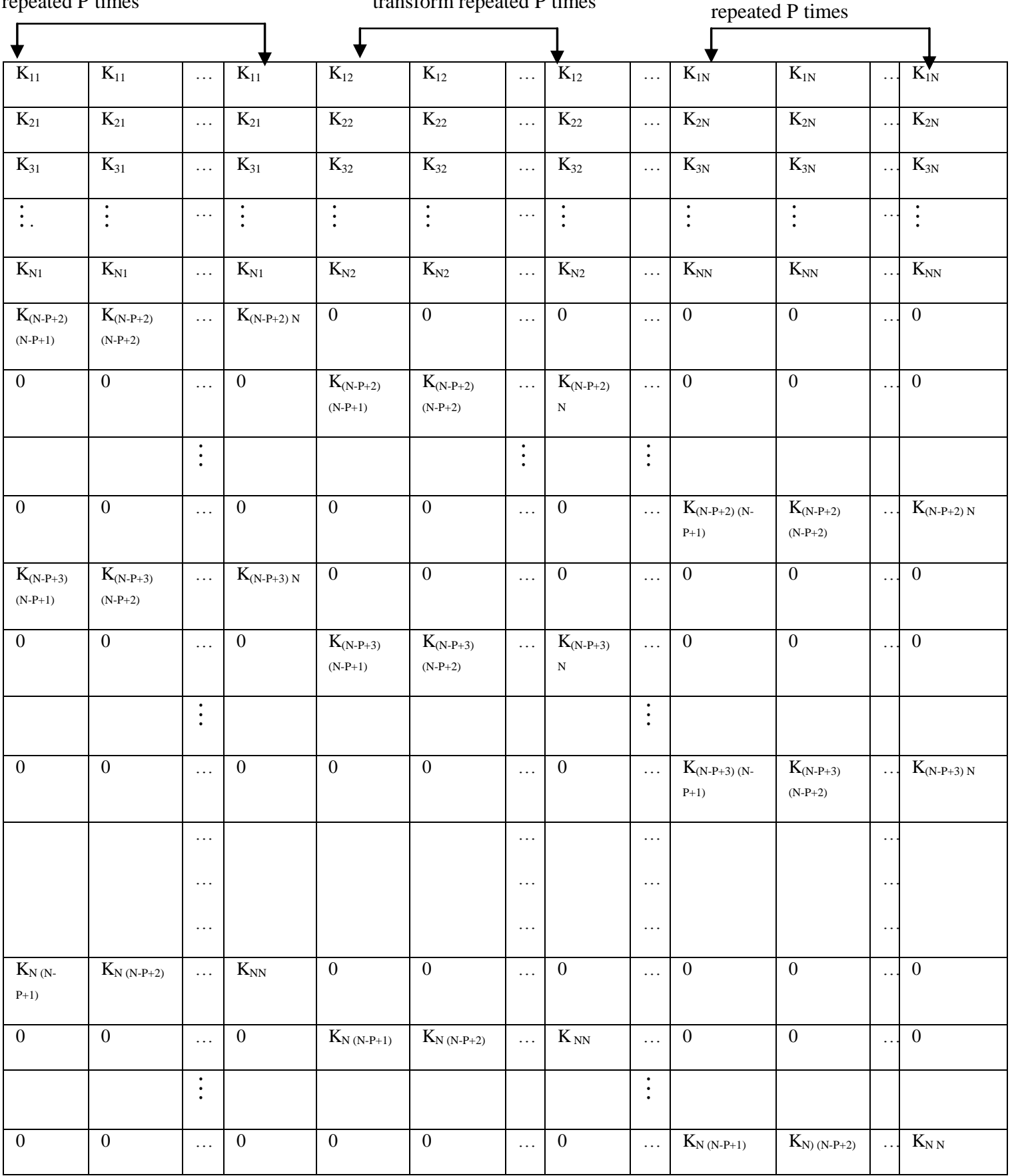

Figure 2 Kekre's Wavelet transform matrix of size MxM generated from Kekre's transform matrix of size $\mathbf{N x N}$. Where M = N $* \mathbf{P}, \mathbf{2} \leq \mathbf{P} \leq \mathbf{N}$.

\section{PPOPOSED ALGORITHM}

Averaging and PCA methods are applied on 9 set of images as described and for all other transform techniques algorithm is given as follows:

1. Take as input two images of same size and of same object or scene taken from two different sensors like visible and infra red images or two images having different focus.

2. If images are colored separate their RGB planes to perform 2D transforms.
3. Perform decomposition of images using different new transforms like Kekre's Wavelet transform, DCT Kekre's Wavelet transform, Hadamard Kekre's Wavelet transform and Walsh Kekre's Wavelet transform etc.

4. Fuse two image components by taking average [2].

5. Resulting fused transform components are converted to image using inverse transform.

6. For colored images combine their separated RGB planes.

7. Compare results of different methods of image fusion using various measures like entropy, standard deviation, mean, mutual information, etc. 


\section{RESULTS AND ANALYSIS}

Above mentioned techniques are tried on pair of three RGB images and six gray images as shown in fig. 4 and results are compared based on measures like entropy, mean, standard deviation and mutual information [3] [11].Figure 5 shows Image fusion by different techniques for visible and infra red
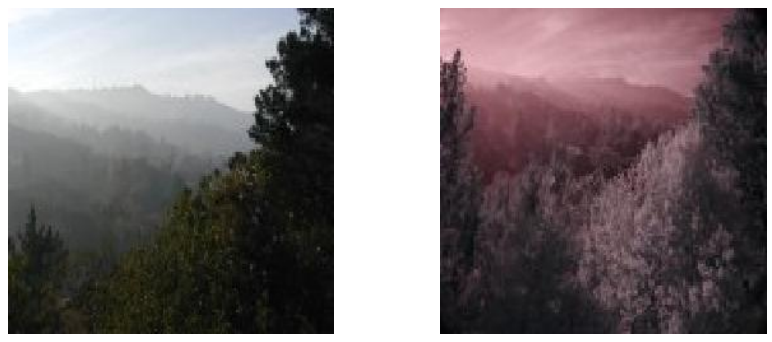

Visible and Infra red Scenery images
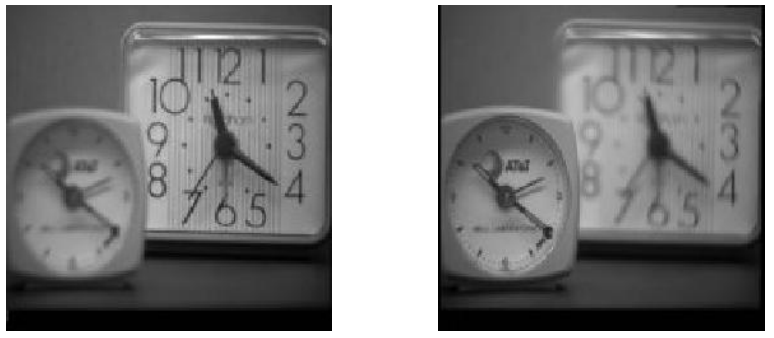

Clock Images
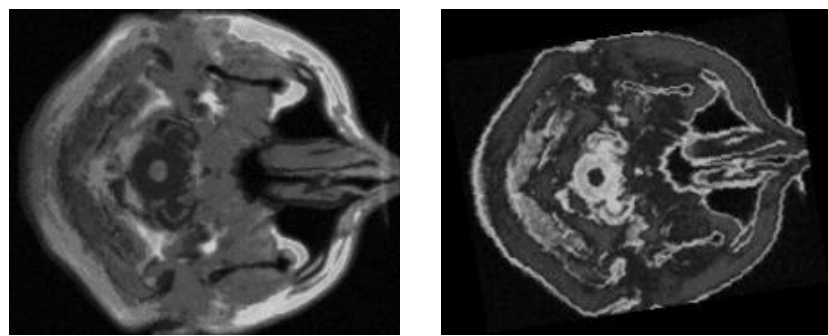

Medical Images
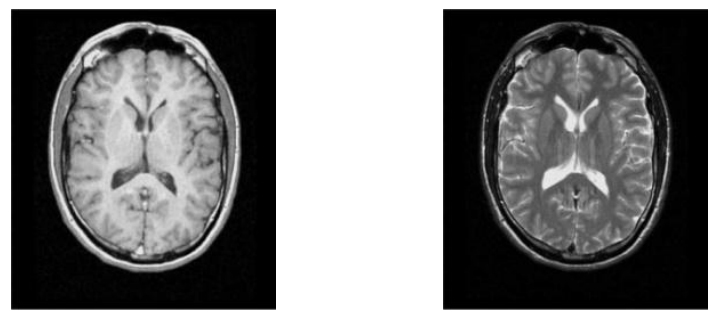

MRI Images
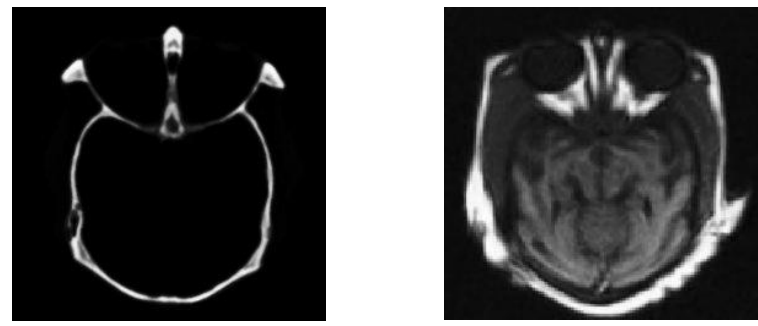

CT and MRI images scenery images. Figure 6 shows Image fusion by different techniques for hill images with different focus. Figure 7 shows Image fusion by different techniques for gray clock images with different focus. Performance evaluation based on above mentioned four measures for color image is given in table 1. Table 2 presents performance evaluation for gray images.
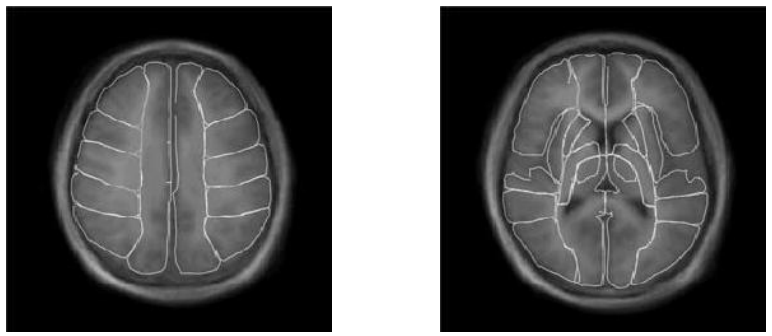

Brain Images
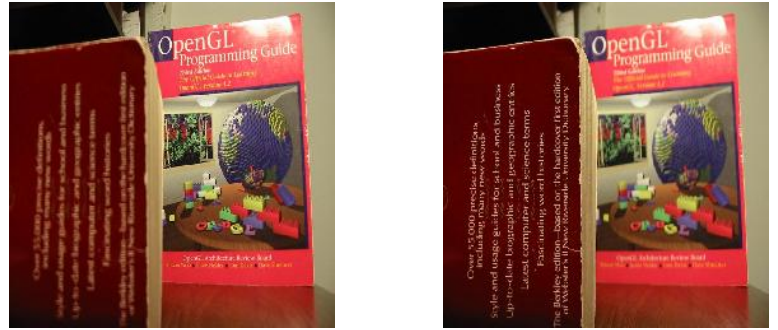

Book Images

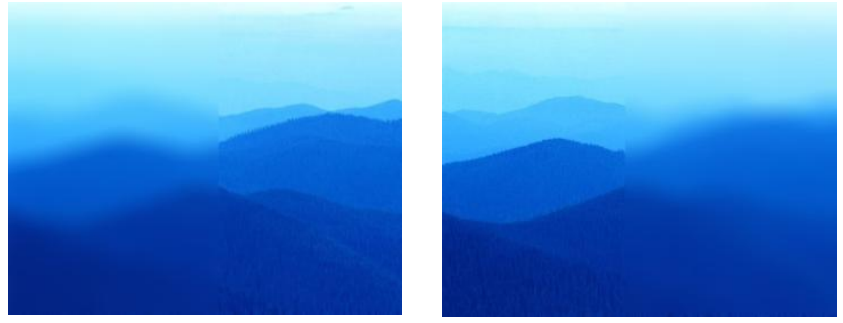

Hill images with different focus
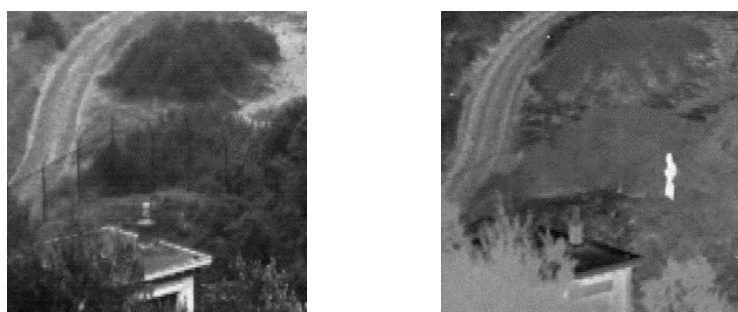

Visible and Infra red gray images

Figure 4 Sample images 


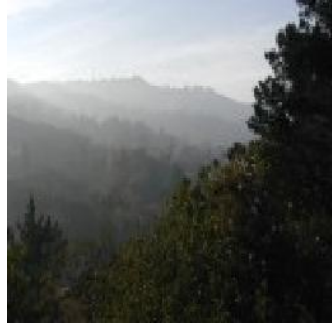

a) visible light Input image 1

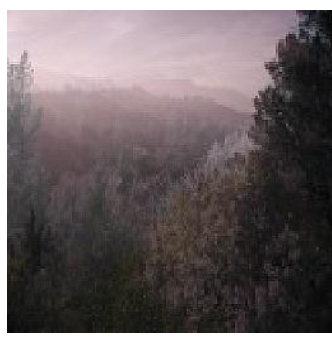

f)Haar wavelet fused image

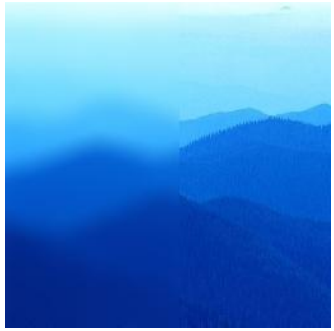

a) Input image 1

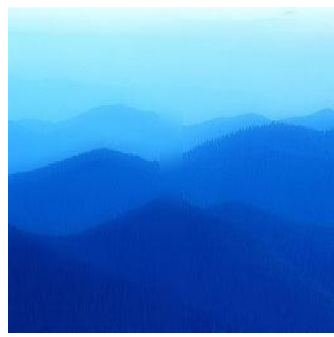

f)Haar wavelet fused image

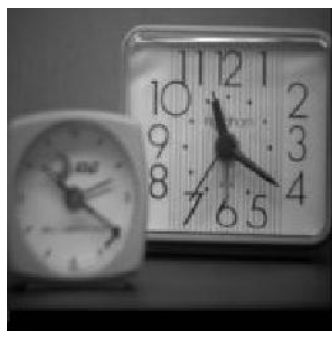

a) Input image 1

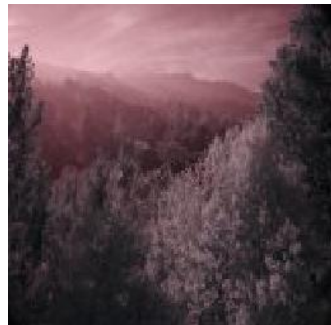

b) infrared light Input image2

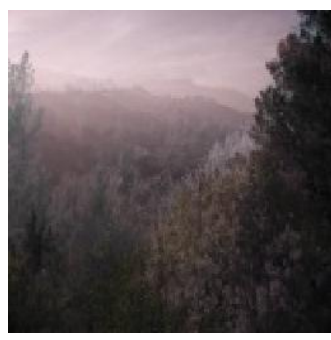

g)Kekre's wavelet fused image

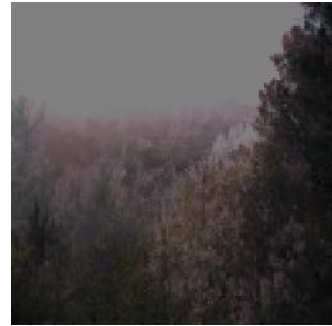

c)Averaging fused image

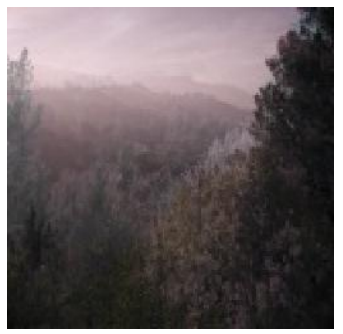

h)DCT Kekre's wavelet fused image

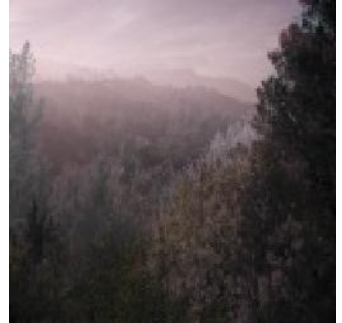

d)DCT fused image

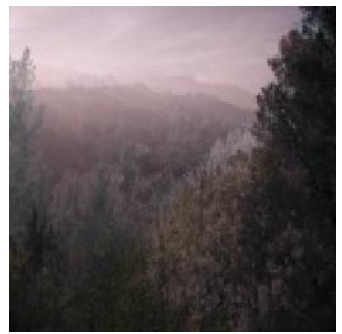

i)Hadamard Kekre's wavelet fused image

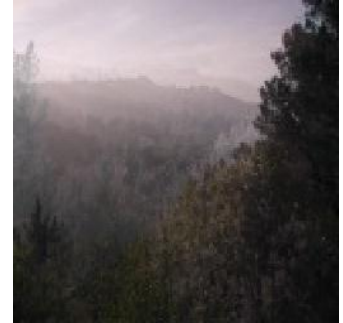

e)PCA fused image

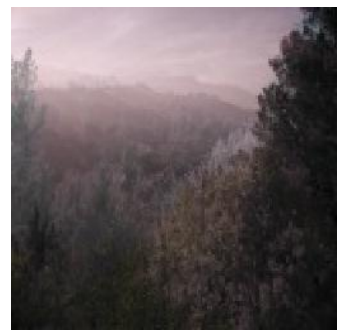

j)Walsh Kekre's wavelet fused image

Figure 5 Image fusion by different techniques visible and infra red images

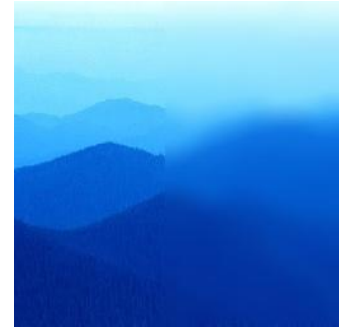

b) Input image 2

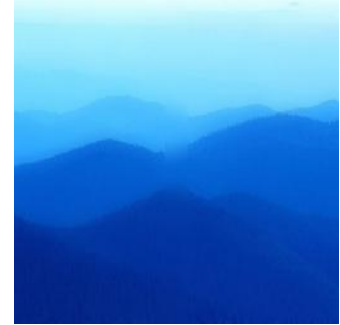

g)Kekre's wavelet fused image

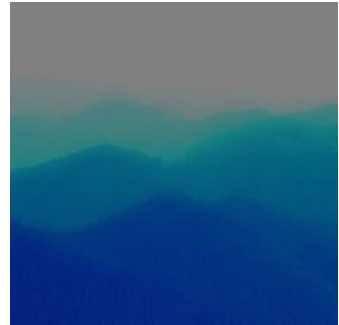

c)Averaging fused image

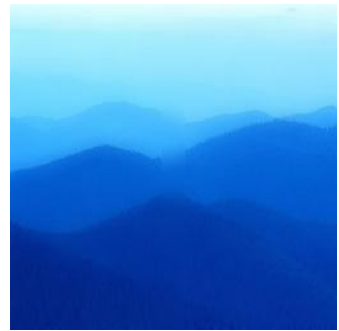

h)DCT Kekre's wavelet fused image

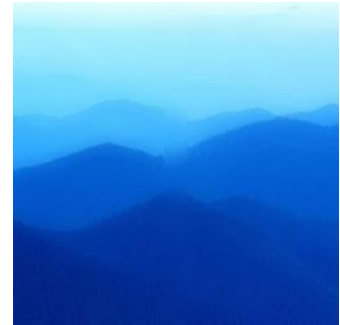

d)DCT fused image

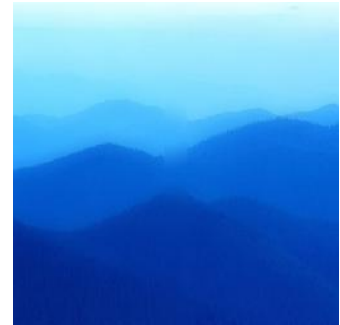

i)Hadamard Kekre's wavelet fused image

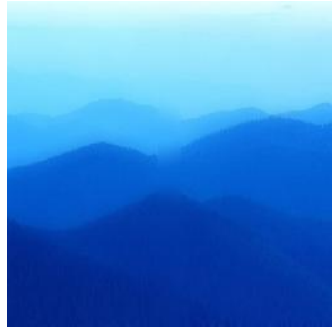

e)PCA fused image

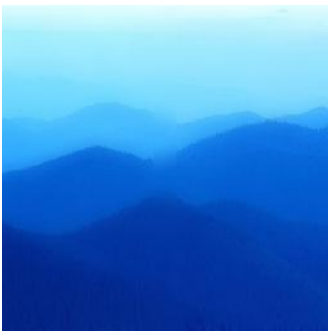

j)Walsh Kekre's wavelet fused image

Figure 6 Image fusion by different techniques for hill images with different focus

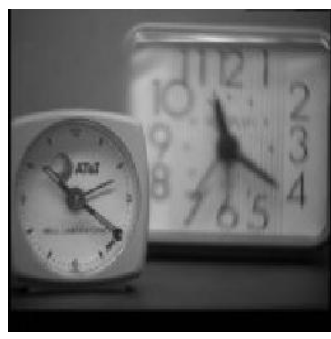

b) Input image 2

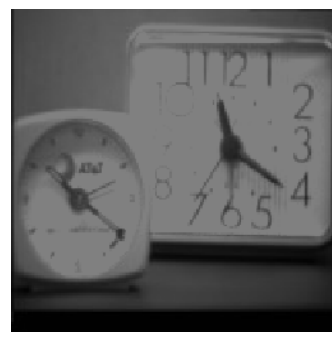

c)Averaging fused image

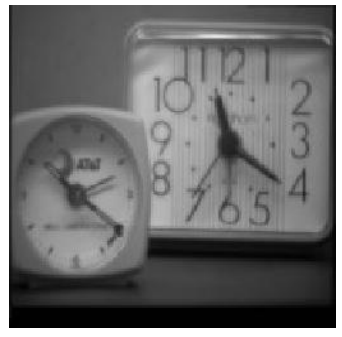

d)DCT fused image

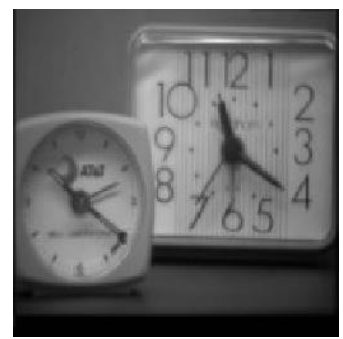

e)PCA fused image 


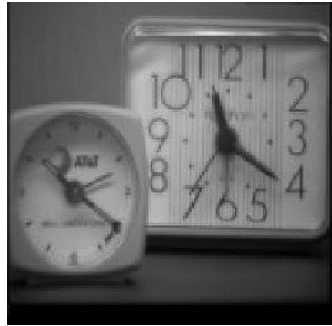

f)Haar wavelet fused image

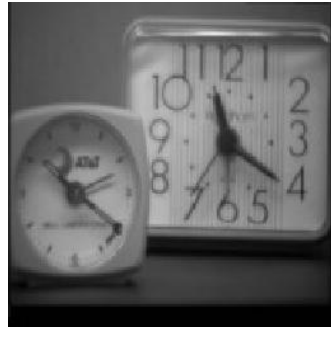

g)Kekre's wavelet fused image

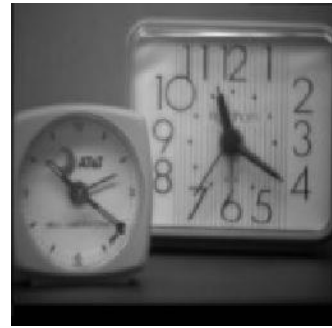

h)DCT Kekre's wavelet fused image

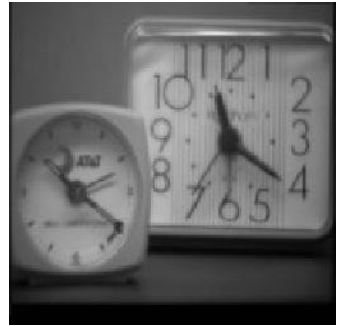

i)Hadamard Kekre's wavelet e fused image

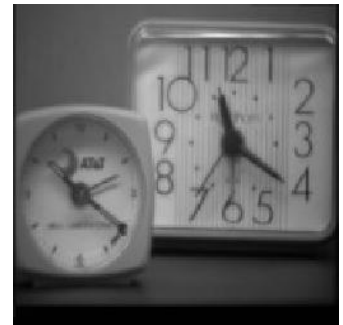

j)Walsh Kekre's wavelet fused image

Figure 7 Image fusion by different techniques images with different focus

Table 1 Performance evaluation for color images

\begin{tabular}{|c|c|c|c|c|c|c|c|c|c|}
\hline & & Averaging & DCT & PCA & $\begin{array}{c}\text { Haar } \\
\text { wavelet }\end{array}$ & $\begin{array}{l}\text { Kekre's } \\
\text { wavelet }\end{array}$ & $\begin{array}{c}\text { DCT- } \\
\text { Kekre's } \\
\text { wavelet }\end{array}$ & $\begin{array}{c}\text { Hadamard } \\
\text { Kekre's } \\
\text { wavelet }\end{array}$ & $\begin{array}{c}\text { Walsh } \\
\text { Kekre's } \\
\text { wavelet }\end{array}$ \\
\hline \multirow{4}{*}{$\begin{array}{c}\text { Hill } \\
\text { Images }\end{array}$} & Mean & 90.7652 & 134.150 & 134.325 & 134.3870 & 134.4092 & 134.3305 & 134.5729 & 134.5729 \\
\hline & SD & 49.6320 & 90.2325 & 90.3185 & 90.3282 & 90.2632 & 90.3409 & 90.3158 & 90.3158 \\
\hline & Entropy & 3.6091 & 7.2593 & 7.2654 & 7.3650 & 7.2610 & 7.2657 & 7.2514 & 7.2514 \\
\hline & MI & 0.3465 & 0.4836 & 0.4892 & 0.4693 & 0.4849 & 0.4831 & 0.4870 & 0.4870 \\
\hline \multirow{4}{*}{$\begin{array}{l}\text { Scenery } \\
\text { images }\end{array}$} & Mean & 74.0107 & 88.6090 & 91.6637 & 88.9377 & 88.8765 & 88.8145 & 89.0465 & 89.0465 \\
\hline & SD & 41.5931 & 64.3474 & 69.9428 & 64.5921 & 64.3860 & 64.3535 & 64.3578 & 64.3578 \\
\hline & Entropy & 5.6304 & 7.4882 & 7.4915 & 7.5192 & 7.4905 & 7.4900 & 7.4894 & 7.4894 \\
\hline & MI & 0.2573 & 0.3619 & 0.3781 & 0.3305 & 0.3651 & 0.3566 & 0.3657 & 0.3657 \\
\hline \multirow{4}{*}{$\begin{array}{l}\text { Book } \\
\text { images }\end{array}$} & Mean & 70.6272 & 83.8643 & 84.0590 & 84.2179 & 84.0735 & 84.0661 & 84.2984 & 84.2984 \\
\hline & SD & 48.6626 & 69.3611 & 69.3732 & 70.8419 & 69.3877 & 69.3626 & 69.3716 & 69.3716 \\
\hline & Entropy & 5.6613 & 7.4697 & 7.4783 & 7.4319 & 7.4802 & 7.4803 & 7.4876 & 7.4876 \\
\hline & MI & 0.3217 & 0.5140 & 0.5140 & 0.4908 & 0.5115 & 7.4803 & 0.5137 & 0.5137 \\
\hline
\end{tabular}

Table 2 Performance evaluation for gray images

\begin{tabular}{|c|c|c|c|c|c|c|c|c|c|}
\hline & Averaging & DCT & PCA & $\begin{array}{c}\text { Haar } \\
\text { wavelet }\end{array}$ & $\begin{array}{c}\text { Kekre's } \\
\text { wavelet }\end{array}$ & $\begin{array}{c}\text { DCT- } \\
\text { Kekre's } \\
\text { wavelet }\end{array}$ & $\begin{array}{c}\text { Hadamard } \\
\text { Kekre's } \\
\text { wavelet }\end{array}$ & $\begin{array}{c}\text { Walsh- } \\
\text { Kekre's } \\
\text { wavelet }\end{array}$ \\
\hline $\begin{array}{c}\text { Clock } \\
\text { images }\end{array}$ & Mean & 89.5221 & 96.3092 & 96.4922 & 96.6174 & 96.4766 & 96.5136 & $\mathbf{9 6 . 7 4 1 9}$ & $\mathbf{9 6 . 7 4 1 9}$ \\
\cline { 2 - 10 } & SD & 40.6857 & 48.9355 & 48.9555 & $\mathbf{4 9 . 3 3 9 3}$ & 49.0089 & 48.9689 & 48.9795 & 48.9795 \\
\cline { 2 - 10 } & Entropy & 5.4238 & 7.3062 & 7.3066 & $\mathbf{7 . 3 3 3 8}$ & 7.3087 & 7.3088 & 7.3057 & 7.3057 \\
\cline { 2 - 10 } & MI & 0.4316 & 0.5185 & 0.5202 & 0.4954 & 0.5182 & 0.5148 & $\mathbf{0 . 5 2 0 6}$ & $\mathbf{0 . 5 2 0 6}$ \\
\hline
\end{tabular}




\begin{tabular}{|c|c|c|c|c|c|c|c|c|c|}
\hline \multirow{4}{*}{$\begin{array}{l}\text { CT MRI } \\
\text { images }\end{array}$} & Mean & 32.1246 & 32.2862 & 51.9930 & 32.5318 & 32.4113 & 32.4366 & 32.6745 & 32.6745 \\
\hline & SD & 32.7642 & 34.8291 & 53.4098 & 36.0796 & 34.8212 & 34.7672 & 34.7752 & 34.7752 \\
\hline & Entropy & 5.7703 & 5.9090 & 6.5409 & 5.9799 & 5.9108 & 5.9231 & 5.8901 & 5.8901 \\
\hline & MI & 0.5744 & 0.5674 & 0.7256 & 0.3982 & 0.5541 & 0.5544 & 0.5901 & 0.5901 \\
\hline \multirow{4}{*}{$\begin{array}{l}\text { Medical } \\
\text { images }\end{array}$} & Mean & 51.9185 & 51.7076 & 53.2289 & 51.9811 & 51.9424 & 51.8908 & 52.1328 & 52.1328 \\
\hline & SD & 36.3854 & 36.8805 & 37.4420 & 38.1760 & 36.9228 & 36.9002 & 36.8938 & 36.8938 \\
\hline & Entropy & 6.5385 & 6.6353 & 6.6308 & 6.7429 & 6.6412 & 6.6385 & 6.6298 & 6.6298 \\
\hline & MI & 0.2693 & 0.2702 & 0.2832 & 0.2290 & 0.2690 & 0.2659 & 0.2768 & 0.2768 \\
\hline \multirow{4}{*}{$\begin{array}{l}\text { Brain } \\
\text { images }\end{array}$} & Mean & 48.8479 & 49.3843 & 49.4806 & 49.5519 & 49.5237 & 49.5185 & 49.6522 & 49.6522 \\
\hline & SD & 49.4465 & 50.7464 & 50.8346 & 51.7821 & 50.8597 & 50.8453 & 50.9315 & 50.9315 \\
\hline & Entropy & 4.9575 & 5.1872 & 5.1890 & 5.2598 & 5.2020 & 5.2105 & 5.2308 & 5.2308 \\
\hline & MI & 0.3862 & 0.3959 & 0.3968 & 0.3844 & 0.3967 & 0.3965 & 0.4019 & 0.4019 \\
\hline \multirow{4}{*}{$\begin{array}{l}\text { MRI } \\
\text { images }\end{array}$} & Mean & 55.6803 & 62.5453 & 65.4645 & 62.7818 & 62.6141 & 62.6906 & 62.8733 & 62.8733 \\
\hline & SD & 58.9193 & 68.3032 & 71.1772 & 69.3133 & 68.4042 & 68.3605 & 68.4069 & 68.4069 \\
\hline & Entropy & 3.7671 & 5.6055 & 5.7225 & 5.7143 & 5.5988 & 5.6298 & 5.6648 & 5.6648 \\
\hline & MI & 0.3426 & 0.3807 & 0.4064 & 0.3567 & 0.3807 & 0.3815 & 0.3876 & 0.3876 \\
\hline \multirow{4}{*}{$\begin{array}{l}\text { Visible } \\
\& \text { infra } \\
\text { red gray } \\
\text { images }\end{array}$} & Mean & 89.5235 & 90.3802 & 102.5909 & 90.6947 & 90.6901 & 90.6423 & 90.8800 & 90.8800 \\
\hline & SD & 19.7397 & 23.1171 & 48.0841 & 24.5829 & 23.1241 & 23.0979 & 23.1082 & 23.1082 \\
\hline & Entropy & 2.9728 & 3.2780 & 3.0784 & 5.3974 & 3.7169 & 3.7410 & 3.2382 & 3.2382 \\
\hline & MI & 0.1829 & 0.1991 & 0.5718 & 0.1777 & 0.2046 & 0.2004 & 0.1987 & 0.1987 \\
\hline
\end{tabular}

From table 1 it is observed that for hill and book images mean indicating brightness is maximum for Hadamard Kekre's wavelet and Walsh Kekre's wavelet technique, while for scenery images it is maximum for PCA. And standard deviation gives clarity and contrast is maximum using DCTKekre's wavelet technique for hill images, while for book images Haar wavelet technique and for scenery images PCA gives best results. Entropy indicating amount of information is carried by the fused image is maximum using Haar wavelet technique for hill and scenery images, while for book images Hadamard Kekre's wavelet and Walsh Kekre's wavelet technique gives best results. Mutual information is maximum by PCA technique for hill and scenery images meaning that quality of fused image is better using this technique, while for book images DCT-Kekre's wavelet technique gives best results.

From table 2 it is observed that for clock and brain images mean and MI are maximum by Hadamard Kekre's wavelet and Walsh Kekre's wavelet technique. Standard deviation and Entropy are maximum using Haar technique. For CT-MRI and MRI images PCA gives best results in terms of all measures. For medical images mean and MI are maximum using PCA technique and SD and entropy are maximum using Haar wavelet technique. For visible and infra red gray images mean, SD and MI are maximum using PCA technique while entropy is maximum using Haar technique.

In all these images if we observe the output of the Kekre's wavelet technique in different combinations it gives best results for some images and for some images it is very close to the output and the major advantage of the matrix is that it can be used for images which are not integral power of 2. 


\section{CONCLUSION}

In this paper many pixel level techniques like Kekre's wavelet technique and its combination with Kekre's transform, DCT, Hadamard and Walsh are implemented and their results are compared with basic techniques such as averaging, PCA, DCT, Haar wavelet. It is observed that the new Kekre's wavelet transform when used for image fusion gives comparatively good results, just closer to the best result and the added advantage is that it can be used for images of any size, not necessarily integer power of 2 .

\section{REFERENCES}

[1] Nianlong Han; Jinxing Hu; Wei Zhang, "Multispectral and SAR images fusion via Mallat and À trous wavelet transform ",18th International Conference on Geoinformatics, 09 September 2010, page(s): 1 - 4

[2] XING Su-xia, CHEN Tian-hua, LI Jing-xian "Image Fusion based on Regional Energy and Standard Deviation" , 2nd International Conference on Signal Processing Systems (ICSPS), 2010,Page(s): 739 -743

[3] Xing Su-xia, Guo Pei-yuan and Chen Tian-hua," Study on Optimal Wavelet Decomposition Level in Infrared and visual Light Image Fusion", International Conference on Measuring Technology and Mechatronics Automation (ICMTMA), 2010 , page(s): $616-619$

[4] Le Song, Yuchi Lin, Weichang Feng, Meirong Zhao "A Novel Automatic Weighted Image Fusion Algorithm", International Workshop on Intelligent Systems and Applications, ISA ,2009 , Page(s): $1-4$

[5] MA. Mohamed and R.M EI-Den" Implementation of Image Fusion Techniques for Multi-Focus Images Using FPGA" 28th National Radio Science Conference (NRSC 2011) April 26-28, 2011, Page(s): 1 - 11

[6] Dr. H. B. Kekre, Archana Athawale, Dipali Sadavarti,"Algorithm to Generate Kekre's Wavelet Transform from Kekre's Transform", International Journal of Engineering Science and Technology, Vol. 2(5), 2010, page(s): 756-767.

[7] Shivsubramani Krishnamoorthy, K.P.Soman, "Implementation and Comparative Study of Image Fusion Algorithms", International Journal of Computer Applications, Volume 9- No.2, November 2010, page(s): 25-35.

[8] V.P.S. Naidu and J.R. Raol," Pixel-level Image Fusion using Wavelets and Principal Component Analysis", Defence Science Journal, Vol. 58, No. 3, May 2008, Page(s): 338-352

[9] Dr. H. B.Kekre, Dr. Tanuja K. Sarode, Sudeep Thepade, Sonal Shroff, "Instigation of Orthogonal Wavelet Transforms using Walsh, Cosine, Hartley, Kekre Transforms and their use in Image Compression", (IJCSIS) International Journal of Computer Science and Information Security, Vol. 9,No. 6, 2011, Page(s) 125133.

[10] Zhang-Shu Xiao, Chong-Xun Zheng,"Medical Image Fusion Based on An Improved Wavelet Coefficient
Contrast", $3^{\text {rd }}$ International Conference on Bioinfromatics and biomedical Engineering, 2009, Page(s)1-4.

[11] H.B.Kekre, Tanuja Sarode, Rachana Dhannawat," Kekre's Wavelet Transform for Image Fusion and Comparison with Other Pixel Based Image Fusion Techniques", vol. 10, No.3 March 2012.

\section{AUTHORS PROFILE}

H. B. Kekre: has received B.E. (Hons.) in Telecomm. Engineering. From Jabalpur University in 1958, M.Tech (Industrial Electronics) from IIT Bombay in 1960, M.S.Engg. (Electrical Engg.) from University of Ottawa in 1965 and Ph.D. (System Identification) from IIT Bombay in $1970 \mathrm{He}$ has worked as Faculty of Electrical Engg. and then HOD Computer Science and Engg. at IIT Bombay. For 13 years he was working as a professor and head in the Department of Computer Engg. At Thadomal Shahani Engineering. College, Mumbai. Now he is Senior Professor at MPSTME, SVKM's NMIMS. He has guided 17 Ph.Ds, more than 100 M.E./M.Tech and several B.E./ B.Tech projects. His areas of interest are Digital Signal processing, Image Processing and Computer Networking. He has more than 270 papers in National / International Conferences and Journals to his credit. He was Senior Member of IEEE. Presently $\mathrm{He}$ is Fellow of IETE and Life Member of ISTE Recently 11 students working under his guidance have received best paper awards. Two of his students have been awarded Ph. D. from NMIMS University. Currently he is guiding ten Ph.D. students.

Tanuja K. Sarode: has Received Bsc.(Mathematics)from Mumbai University in 1996, Bsc.Tech.(Computer Technology) from Mumbai University in 1999, M.E. (Computer Engineering) degree from Mumbai University in 2004, Ph.D. from Mukesh Patel School of Technology, Management and Engineering, SVKM's NMIMS University, Vile-Parle (W), Mumbai, INDIA. She has more than 12 years of experience in teaching. Currently working as Assistant Professor in Dept. of Computer Engineering at Thadomal Shahani Engineering College, Mumbai. She is life member of IETE, member of International Association of Engineers (IAENG) and International Association of Computer Science and Information Technology (IACSIT), Singapore. Her areas of interest are Image Processing, Signal Processing and Computer Graphics. She has more than 100 papers in National /International Conferences/journal to her credit.

Rachana Dhannawat: has received B.E. degree from Sant Gadg ebaba Amaravati University in 2003. She is pursuing M.E. from Mumbai University. She has more than 8years of experience in teaching. Currently working as assistant professor in Usha Mittal Institute of Technology, S.N.D.T. Univesity, Mumbai. She is life member of ISTE. Her area of interest are Image Processing,Networking, Computer graphics and algorithms. She has one national and one international journal paper to her credit. 